Journal of Patient-Centered

7-19-2021

\title{
Loneliness in Primary Care Patients: Relationships With Body Mass Index and Health Care Utilization
}

\author{
Tamara K. Oser \\ Siddhartha Roy \\ Jessica Parascando \\ Rebecca Mullen \\ Julie Radico \\ Alexis Reedy-Cooper \\ Jennifer Moss
}

Follow this and additional works at: https://aah.org/jpcrr

Part of the Community Health and Preventive Medicine Commons, Family Medicine Commons, Health Services Research Commons, Other Mental and Social Health Commons, and the Primary Care Commons

\section{Recommended Citation}

Oser TK, Roy S, Parascando J, Mullen R, Radico J, Reedy-Cooper A, Moss J. Loneliness in primary care patients: relationships with body mass index and health care utilization. J Patient Cent Res Rev.

2021;8:239-47. doi: 10.17294/2330-0698.1808

Published quarterly by Midwest-based health system Advocate Aurora Health and indexed in PubMed Central, the Journal of Patient-Centered Research and Reviews (JPCRR) is an open access, peer-reviewed medical journal focused on disseminating scholarly works devoted to improving patient-centered care practices, health outcomes, and the patient experience. 


\title{
Loneliness in Primary Care Patients: Relationships With Body Mass Index and Health Care Utilization
}

\author{
Tamara K. Oser, MD, ${ }^{1}$ Siddhartha Roy, DrPH,${ }^{2}$ Jessica Parascando, MPH, ${ }^{2}$ Rebecca Mullen, MD, ${ }^{1}$ \\ Julie Radico, PsyD, ${ }^{2}$ Alexis Reedy-Cooper, MD, ${ }^{2}$ Jennifer Moss, $\mathrm{PhD}^{2}$ \\ ${ }^{1}$ Department of Family Medicine, University of Colorado School of Medicine, Aurora, CO; ' Department of Family and \\ Community Medicine, Penn State College of Medicine, Hershey, PA
}
Purpose Rates of loneliness and obesity have increased in recent decades. Loneliness and obesity independently have been found to be risk factors for negative physical and mental health outcomes. This study examined the rates and interrelationships of loneliness, body mass index (BMI), and health care utilization in a primary care setting.
Methods A cross-sectional survey of adult patients presenting for outpatient care at 7 family medicine clinical practices in Pennsylvania was conducted. Survey questions included self-reported measures of loneliness, height/weight, number of health care visits, and potential confounders (eg, sociodemographic variables, health status). Bivariate and multivariable linear regression models were used to analyze associations among loneliness, BMI, and health care utilization.

Results In all, 464 eligible patients returned surveys for an overall response rate of 26\%. Mean (standard deviation) loneliness score was 4.2 (1.7), mean BMI was 30.4 (7.6), and mean number of visits in year prior was 2.7 (3.6). On bivariate analysis, BMI was positively associated with loneliness (effect estimate: $0.50 ; \mathrm{P}=0.03$ ). On multivariable analysis, $\mathrm{BMI}$ was negatively associated with attending religious services and self-reported physical health and positively associated with self-reported mental health $(\mathrm{P}<0.05$ for all), but not associated with loneliness. While not associated with loneliness, health care utilization was negatively associated with Hispanic ethnicity, marital status, and self-reported physical health $(\mathrm{P}<0.05$ for all).

Conclusions Given the detrimental effects loneliness and obesity have on health outcomes, it might be prudent for health care providers to prioritize health concerns for their patients by assessing loneliness and counseling regarding associated risks, particularly in patients with obesity. ( $J$ Patient Cent Res Rev. 2021;8:239-247.)

Keywords loneliness; obesity; body mass index; health care utilization; outpatient care

$\mathrm{L}$ oneliness is a growing concern in the United States due to a multitude of reasons, including rapid growth of the elderly population who are at increased risk for loneliness and its negative impacts on physical and mental health. More than one-third of adults 45 years old and older feel lonely, and approximately one-fourth of adults 65 years old and older feel socially isolated. ${ }^{1}$ Additionally, loneliness is thought to increase risk of mortality by $26 \%{ }^{2}$

Corresponding author: Tamara K. Oser, MD,

Department of Family Medicine, University of Colorado Anschutz Medical Campus, 12631 E. 17th Ave., Box F496, Aurora, CO 80045 (tamara.oser@cuanschutz.edu)
Defined as the distressing emotion resulting from the absence (or perceived absence) of expected meaningful interpersonal relationships, ${ }^{3}$ loneliness carries serious health implications. These include associations with a variety of negative health outcomes such as hypertension, stroke, heart disease, depression, and suicidality. ${ }^{4-7}$ For example, studies have shown that loneliness is associated with increased prevalence of stroke and increased risk of poststroke depression, ${ }^{6,8,9}$ and patients who experienced stroke have reported higher perceived social isolation than age-matched healthy individuals. ${ }^{6,9}$ Additionally, Lofvenmark et al identified a potential link between loneliness and heart failure in a sample of 149 patients with heart failure in which $20 \%$ of patients reported being lonely, and those who reported being lonely had more days hospitalized and more hospital readmissions. ${ }^{6,10}$ 
Given its high prevalence and potential serious consequences, loneliness has gained global attention. National health and business leaders have deemed loneliness in the United States an epidemic, ${ }^{11}$ with researchers calling to make social connection a national public health priority ${ }^{12}$ and the National Academies of Sciences, Engineering, and Medicine recommending increased emphasis on the role of the health care sector in addressing loneliness. ${ }^{1}$ More recently, the COVID-19 pandemic and the incumbent social isolation that resulted from widespread public recommendations and requirements for people to distance, quarantine, and/ or isolate may make loneliness an even greater clinical priority going forward. ${ }^{13,14}$ In order for health care practices to successfully address loneliness in patients, we must understand the presentation of loneliness in primary care and the relationship between loneliness and common chronic conditions, including obesity (ie, body mass index $[\mathrm{BMI}]$ of $\geq 30$ ).

Loneliness and obesity are common in primary care patients and individually associated with high health care utilization and poor self-rated health. ${ }^{15-19}$ The exact relationship between loneliness and obesity remains unclear, but they both have a negative impact on health. ${ }^{6}$ One study found loneliness to be associated with poor sleep and poor sleep to be associated with obesity and other negative health outcomes. ${ }^{20}$ In 2006, Morse et al studied 714 patients and found $40.2 \%$ to be lonely and $63.8 \%$ of those who reported being lonely to have nighttime-eating symptoms. ${ }^{21}$ Recent interest in these relationships has increased given the rise of obesity, which has spurred research revealing the relationship of psychosocial factors with health care and health outcomes in people with obesity. ${ }^{22,23}$ Prior literature has illustrated that higher BMI is associated with higher levels of loneliness in the general population. ${ }^{24,25}$ Individuals with loneliness are further known to have higher risk of metabolic syndrome. ${ }^{26,27}$ A 2010 study found that each 1 -unit increase in loneliness was associated with a $10 \%$ increase in the odds of a person meeting the criteria for metabolic syndrome. ${ }^{27}$ Despite this prior research, to our knowledge, no studies have investigated the direct impact of loneliness and obesity on health care utilization. Prior research has shown the potential influence of gender on loneliness, obesity, and health care utilization, but results were mixed. ${ }^{7}$ Therefore, assessing the relationship between loneliness and BMI as well as loneliness and health care utilization through the gender lens could identify potential gender disparities.

Currently, there are high levels of adult obesity in Pennsylvania, from which this study's respondents were recruited. According to the profile for Dauphin
County (central Pennsylvania's most populous county), $30 \%$ of inhabitants are considered obese, similar to the state average but less than the national average of approximately $40 \%{ }^{13}$ The aim of this study was to describe the relationships among BMI, loneliness, and health care utilization in patients presenting to outpatient primary care practices for routine care. We hypothesized that there would be a positive association between loneliness and BMI in this patient care population. Additionally, we hypothesized that loneliness would be associated with increased health care utilization.

\section{METHODS}

This study was a cross-sectional survey of adult patients presenting for outpatient care between July 22, 2019, and July 26, 2019, at 7 family medicine clinical practices in Pennsylvania. The study was deemed exempt (ie, nonhuman subjects research) by the institutional review board at Penn State College of Medicine.

\section{Setting and Population}

A total of 7 practices, all affiliated with Penn State College of Medicine, located in 3 Pennsylvania counties participated in the study. On average, these counties have populations 1) that are $74.4 \%$ non-Hispanic White, $8.6 \%$ non-Hispanic Black, and $11.4 \%$ Hispanic; 2) with private insurance among $74.1 \%$ of residents; and 3 ) with median annual household incomes of $\$ 74,628$. The participating practices were predominantly suburban, with significant rural representation as well.

Participants were recruited by convenience sampling. Patients who were age 18 years or older and fluent in written English or Spanish were asked to complete a paper survey after checking in for their visit. A summary of the study was included with the survey. Completed surveys were placed by the patient in a locked box located in a secure location in the practice. Surveys were collected until the end of a consecutive 5-day collection period. Patients were not compensated for survey completion.

Response rates were calculated for each of the 7 clinics as the number of completed surveys divided by the number of adult patients with completed visits in that week.

\section{Measures}

Given that surveys were completed anonymously, all data were self-reported (ie, not linked or verified with data from the electronic health record). Survey questions included measures of loneliness as well as sociodemographics, health status, health care utilization, height, and weight. These covariates were selected because they have been associated with BMI or health care utilization in other studies. ${ }^{28,29}$ Sociodemographic information included 
age, sex, zip code, race/ethnicity, length of time at current address, current marital/cohabitation status, and frequency of attendance at religious services. Completion of the survey was voluntary, and respondents could choose whether or not to respond to any individual item. Missingness was $<10 \%$ across all items.

We used the Three-Item Loneliness Scale to measure our predictor variable, which was loneliness. ${ }^{30}$ This shortened screening tool has demonstrated reliability and correlation to the full 20-item Revised UCLA Loneliness Scale. ${ }^{31}$ Items assess lack of companionship, feeling left out, and feeling isolated from others. ${ }^{30}$ Respondents replied on a 3-point scale (hardly ever, some of the time, or often), corresponding to scores ranging from 1 to 3 for each item, and received a total score of 3-9. A total score of 6 or above was coded as "lonely;" all others were coded as "non-lonely." 32 Participants also were asked how often they saw or talked to people who they cared about and felt close to (less than once a week, 1-2 times a week, 3-5 times a week, or 5 or more times a week).

Participants were asked to report on their health using a measure adapted from the 36-Item Short Form Survey (SF-36) instrument. ${ }^{33}$ Overall health status was measured by responses to 2 items that read, "In general, how would you rate your [physical/mental] health" on a 5-point scale $(1=$ poor, $2=$ fair, $3=$ good, $4=$ very good, $5=$ excellent). Health care utilization, the second outcome variable, was captured in a question adapted from the Behavioral Risk Factor Surveillance System (BRFSS), for which respondents self-reported the number of times ("excluding today") they had seen a health care provider in the past 2 weeks, 2 months, and 1 year. ${ }^{34}$

Height and weight responses were converted to create one of our outcome variables, BMI, using an online converter.

All material was available in English and Spanish. When survey items were not readily available in Spanish, questions were translated by a study team member who was bilingual and a certified medical interpreter. Prior to deployment, the survey was pilot tested with a small group of volunteers and, on average, took 70 seconds to complete.

\section{Statistical Analysis}

Data analysis was performed using $\mathrm{SAS}^{\circledR} 9.4$ software $^{35}$ (SAS Institute Inc.). The main analysis assessed the continuous loneliness scale score. Age, length of time at current address, and frequency of attendance at religious services were analyzed as continuous variables. Sex, marital status, and race/ethnicity were analyzed as categorical variables. Demographic variables were analyzed using basic descriptive statistics, and then differences by sex were assessed using $t$-tests or chisquared tests as appropriate to the noted distribution.

Associations of loneliness with BMI and health care utilization were analyzed with bivariate and multivariable linear regressions for each, with a two-sided P-value alpha of 0.05 . Based on previous studies indicating systematic sex differences in loneliness and its relationship with other variables, analyses are presented for the overall sample and grouped by sex. We assessed moderation effects between loneliness and each control variable in their relationship with BMI and health care utilization (separately) using multiplicative interaction terms; however, none of the observed variables interacted statistically with loneliness in their relationship with the outcome variables.

\section{RESULTS \\ Sample Characteristics}

A total of 469 patients returned completed surveys; 5 surveys were completed by individuals under 18 years of age, or did not include age at all, and were therefore discarded. The total number of surveys analyzed was 464 , out of 1769 patient visits, for an overall response rate of $26 \%$. Response rates ranged from $16 \%$ to $63 \%$ at individual clinics. Of the 464 surveys analyzed, $97 \%$ were completed in English and 3\% in Spanish. The majority of survey participants were female $(71.6 \%)$ and White $(72 \%)$, and more than half were married/living with a partner (Table 1). Across sociodemographic characteristics, significant differences were found between males and females for race/ethnicity only $(\mathrm{P}=0.01)$. The mean age of respondents was 50.8 years (standard deviation [SD]: 18.1).

Participants' mean loneliness score was 4.2 (SD: 1.7). Of the 434 respondents who provided survey data on loneliness, $102(23.5 \%)$ were classified as lonely (ie, score of $\geq 6$ ) and the remaining 332 respondents who reported a score of $<6$ were classified as not lonely. All ensuing results were generated from analyzing the construct of loneliness on a continuum. While additional analysis that examined loneliness as a dichotomous measure (ie, lonely vs non-lonely) was performed, presence of loneliness was not associated with BMI or health care utilization, overall or when stratified by sex, per bivariate linear regression.

\section{Loneliness and BMI}

Participants' mean BMI was 30.4 (SD: 7.6), ranging from 16.3 to 63.4 (46 surveys, or $9.9 \%$, had missing data on BMI). Table 2 presents the unadjusted and adjusted regression coefficient estimates (est.) and standard errors (SE) to summarize the strength of associations between study variables and BMI for the overall study sample, for males only, and for females only. 
Table 1. Participant Demographics $(\mathrm{N}=464)$

\begin{tabular}{|c|c|c|c|c|}
\hline & $\begin{array}{l}\text { Overall } \\
(\mathrm{N}=464)\end{array}$ & $\begin{array}{c}\text { Male } \\
(n=130)\end{array}$ & $\begin{array}{l}\text { Female } \\
(n=332)\end{array}$ & $\boldsymbol{P}$ \\
\hline Race/Ethnicity, n (\%) & & & & 0.01 \\
\hline Non-Hispanic White & $336(72.4)$ & $97(74.6)$ & $239(72.0)$ & \\
\hline Non-Hispanic Black/African American & $59(12.7)$ & $10(7.7)$ & $48(14.5)$ & \\
\hline Hispanic & $42(9.1)$ & $16(12.3)$ & $26(7.8)$ & \\
\hline Other & $27(5.8)$ & $7(5.4)$ & $19(5.7)$ & \\
\hline Marital status, n (\%) & & & & 0.77 \\
\hline Single/Other & $202(43.5)$ & $52(40.0)$ & $149(44.9)$ & \\
\hline Married/Living with partner & $260(56.0)$ & $78(60.0)$ & $181(54.5)$ & \\
\hline Social connectedness (seeing or talking to people), $\mathrm{n}(\%)$ & & & & 0.85 \\
\hline$\leq 5$ times per week & $164(35.3)$ & $47(36.2)$ & $117(35.2)$ & \\
\hline$>5$ times per week & $291(62.7)$ & $80(61.5)$ & $209(63.0)$ & \\
\hline Religion services, n (\%) & & & & 0.14 \\
\hline Few times per year or never & $280(60.3)$ & $85(65.4)$ & $195(58.7)$ & \\
\hline At least $1-2$ times per month & $172(37.1)$ & $44(33.9)$ & $126(38.0)$ & \\
\hline Number of years living at same address, $n(\%)$ & & & & 0.24 \\
\hline$\leq 3$ years & $140(30.2)$ & $36(27.7)$ & $102(30.7)$ & \\
\hline$>3$ years & $314(67.7)$ & $92(70.8)$ & $222(66.9)$ & \\
\hline Age [range: 18-91], mean years (SD) & $50.8(18.1)$ & $52.2(16.7)$ & $50.3(18.7)$ & 0.30 \\
\hline Self-reported mental health [range:1-5], mean score (SD) & $3.6(1.1)$ & $3.7(1.1)$ & $3.5(1.1)$ & 0.12 \\
\hline Self-reported physical health [range: $1-5]$, mean score (SD) & $3.4(1.0)$ & $3.4(1.0)$ & $3.3(1.0)$ & 0.28 \\
\hline Loneliness [range: 3-9], mean score (SD) & $4.2(1.7)$ & $4.0(1.5)$ & $4.3(1.7)$ & 0.11 \\
\hline Body mass index [range: 16.3-63.4], mean (SD) & $30.4(7.6)$ & $30.1(6.2)$ & $30.6(8.1)$ & 0.55 \\
\hline Health care utilization in past year [range: $0-48]$, mean (SD) & $2.7(3.6)$ & $3.1(4.9)$ & $2.6(2.9)$ & 0.25 \\
\hline
\end{tabular}

Completion of individual items on survey was voluntary; missing responses resulted in some categories not totaling 464. $S D$, standard deviation.

In the unadjusted bivariate analysis (Model 1), greater loneliness was associated with increased BMI in the overall study population (est. of 0.50 [SE: 0.23 ]; $\mathrm{P}=0.03$ ); however, this relationship was not statistically significant when adjusted for the control variables in Model 2 (Table 2; Figure 1). In the adjusted multivariable analysis (Model 2), BMI was negatively associated with attending a religious service 1-2 times per month or more (est. of -3.10 [SE: 0.82]; $\mathrm{P}<0.001$ ), positively associated with self-reported mental health (est. of 1.11, [SE: 0.48]; $\mathrm{P}=0.02$ ), and negatively associated with self-reported physical health (est. of -2.28 [SE: 0.49]; $\mathrm{P}<0.001$ ).

When applying a multivariable model and stratifying by sex (Model 2), loneliness was not significantly associated with BMI among males but was positively associated with BMI for females (est. of 0.73 [SE: 0.36]; $\mathrm{P}=0.04$ ) (Table 2; Figure 1). As with the combined sample, BMI was negatively associated with attendance at religious services and self-reported physical health for males and females $(\mathrm{P}<0.05$ for all). BMI was positively associated with self-reported mental health for females (est. of 1.34 [SE: 0.61]; $\mathrm{P}=0.03$ ), but not for males.

\section{Loneliness and Health Care Utilization}

The mean number of health care visits in the year prior to survey was 2.7 (SD: 3.6), ranging from 0 to 48 (32 surveys, or $6.9 \%$, had missing data on visits). The distribution of visits was right-skewed, with a median of 2.0 visits and an interquartile range of $1-3$. For the overall sample, loneliness was not associated with health care utilization per Model 1 (Table 3). In multivariable analysis (Model 2), health care utilization was negatively associated with Hispanic ethnicity $(\mathrm{P}=0.03)$, being married or living with a partner $(\mathrm{P}=0.04)$, and selfreported physical health $(\mathrm{P}<0.01)$ (Table 3; Figure 2). 
Table 2. Linear Regression Results Examining Bivariate (Model 1) and Multivariable (Model 2) Relationships Between Body Mass Index and Study Variables

\begin{tabular}{|c|c|c|c|c|c|c|}
\hline \multirow[b]{2}{*}{ Variable } & \multicolumn{3}{|c|}{ Model $1^{a}$} & \multicolumn{3}{|c|}{ Model $2^{b}$} \\
\hline & $\begin{array}{l}\text { Overall, } \\
\text { est. (SE) }\end{array}$ & $\begin{array}{l}\text { Male, } \\
\text { est. (SE) }\end{array}$ & $\begin{array}{l}\text { Female, } \\
\text { est. (SE) }\end{array}$ & $\begin{array}{l}\text { Overall, } \\
\text { est. (SE) }\end{array}$ & $\begin{array}{l}\text { Male, } \\
\text { est. (SE) }\end{array}$ & $\begin{array}{l}\text { Female, } \\
\text { est. (SE) }\end{array}$ \\
\hline Loneliness & $0.50(0.23)^{*}$ & $0.42(0.40)$ & $0.52(0.28)$ & $0.50(0.29)$ & $-0.53(0.53)$ & $0.73(0.36)^{*}$ \\
\hline \multicolumn{7}{|l|}{ Race/Ethnicity (ref: non-Hispanic White) } \\
\hline Non-Hispanic Black/African American & $1.56(1.17)$ & $2.88(2.42)$ & $1.35(1.73)$ & $2.28(1.20)$ & $2.85(2.36)$ & $2.45(1.40)$ \\
\hline Hispanic & $0.89(1.33)$ & $-0.44(1.77)$ & $1.73(1.81)$ & $1.07(1.50)$ & $-4.16(2.11)$ & $3.46(2.00)$ \\
\hline Other & $-0.85(1.67)$ & $-4.76(2.60)$ & $0.92(2.16)$ & $-2.28(1.95)$ & $-5.21(2.82)$ & $-1.44(2.57)$ \\
\hline Married/Living with partner (ref: single/other) & $0.14(0.75)$ & $0.21(1.19)$ & $0.12(0.94)$ & $1.22(0.80)$ & $0.34(1.34)$ & $1.86(1.02)$ \\
\hline $\begin{array}{l}\text { Social connectedness (ie, seeing other } \\
\text { people }>5 \text { times per week) (ref: } \leq 5 x \text { ) }\end{array}$ & $0.39(0.78)$ & $-0.40(1.19)$ & $0.72(0.99)$ & $1.24(0.82)$ & $-0.35(1.40)$ & $1.27(1.03)$ \\
\hline $\begin{array}{l}\text { Attends religious services } 1-2 \text { times per month } \\
\text { or more (ref: few times per year or never) }\end{array}$ & $-2.34(0.77)^{\dagger}$ & $-2.09(1.20)$ & $-2.44(0.97)^{*}$ & $-3.10(0.82)^{\ddagger}$ & $-2.59(1.30)^{*}$ & $-3.41(1.02)^{\dagger}$ \\
\hline$>3$ years living at same address (ref: $\leq 3$ years) & $0.71(0.82)$ & $1.08(1.30)$ & $0.57(1.02)$ & $-0.02(0.86)$ & $0.39(1.44)$ & $-0.31(1.07)$ \\
\hline Age & $0.01(0.02)$ & $-0.03(0.04)$ & $0.03(0.03)$ & $0.01(0.03)$ & $-0.06(0.04)$ & $0.03(0.03)$ \\
\hline Mental health & $-0.77(0.34)^{*}$ & $-0.91(0.55)$ & $-0.71(0.42)$ & $1.11(0.48)^{*}$ & $0.06(0.74)$ & $1.34(0.61)^{*}$ \\
\hline Physical health & $-2.28(0.36)^{\ddagger}$ & $-2.14(0.56)^{\ddagger}$ & $-2.33(0.45)^{\ddagger}$ & $-2.28(0.49)^{\ddagger}$ & $-2.58(0.79)^{\dagger}$ & $-2.81(0.61)^{\ddagger}$ \\
\hline Adjusted $R^{2}$ & & & & $12.7 \%$ & $13.9 \%$ & $13.3 \%$ \\
\hline
\end{tabular}

${ }^{a}$ Model 1 was unadjusted.

${ }^{b}$ Model 2 was adjusted for race/ethnicity, marital status, seeing other people $>5 x$ per week, religious services, living at the same address, age, self-rated mental health, self-rated physical health, and sex.

${ }^{*} P<0.05 ;{ }^{\dagger} P<0.01 ; \neq P<0.001$.

est., estimate; SE, standard error.

Table 3. Linear Regression Results Examining Relationships Between Health Care Utilization and Study Variables

\begin{tabular}{|c|c|c|c|c|c|c|}
\hline \multirow[b]{2}{*}{ Variable } & \multicolumn{3}{|c|}{ Model $1^{\mathrm{a}}$} & \multicolumn{3}{|c|}{ Model $2^{b}$} \\
\hline & $\begin{array}{l}\text { Overall, } \\
\text { est. (SE) }\end{array}$ & $\begin{array}{l}\text { Male, } \\
\text { est. (SE) }\end{array}$ & $\begin{array}{l}\text { Female, } \\
\text { est. (SE) }\end{array}$ & $\begin{array}{l}\text { Overall, } \\
\text { est. (SE) }\end{array}$ & $\begin{array}{l}\text { Male, } \\
\text { est. (SE) }\end{array}$ & $\begin{array}{l}\text { Female, } \\
\text { est. (SE) }\end{array}$ \\
\hline Loneliness & $0.16(0.11)$ & $0.20(0.31)$ & $0.16(0.10)$ & $0.07(0.15)$ & $-0.14(0.44)$ & $0.17(0.15)$ \\
\hline \multicolumn{7}{|l|}{ Race/Ethnicity (ref: non-Hispanic White) } \\
\hline Non-Hispanic Black/African American & $-0.74(0.52)$ & $-1.63(1.62)$ & $-0.41(0.48)$ & $-0.76(0.60)$ & $-1.84(1.78)$ & $-0.51(0.57)$ \\
\hline Hispanic & $-1.24(0.70)$ & $-1.81(1.55)$ & $-1.02(0.74)$ & $-1.84(0.86)^{*}$ & $-2.45(1.85)$ & $-1.56(0.94)$ \\
\hline Other & $-0.99(0.73)$ & $-1.96(1.91)$ & $-0.61(0.72)$ & $-0.70(0.95)$ & $-0.87(2.19)$ & $-0.38(1.01)$ \\
\hline Married/Living with partner (ref: single/other) & $-0.71(0.35)^{*}$ & $-1.84(0.90)^{*}$ & $-0.32(0.34)$ & $-0.86(0.41)^{*}$ & $-1.81(1.11)$ & $-0.32(0.42)$ \\
\hline $\begin{array}{l}\text { Social connectedness (ie, seeing other } \\
\text { people }>5 \text { times per week) (ref: } \leq 5 x)\end{array}$ & $0.49(0.36)$ & $0.99(0.93)$ & $0.32(0.35)$ & $0.81(0.42)$ & $1.92(1.16)$ & $0.46(0.42)$ \\
\hline $\begin{array}{l}\text { Attends religious services } 1-2 \text { times per month } \\
\text { or more (ref: few times per year or never) }\end{array}$ & $0.06(0.36)$ & $-0.99(0.93)$ & $0.50(0.35)$ & $0.56(0.42)$ & $-0.66(1.10)$ & $0.88(0.42)^{*}$ \\
\hline$>3$ years living at same address (ref: $\leq 3$ years) & $0.15(0.38)$ & $1.34(0.99)$ & $-0.34(0.37)$ & $0.30(0.45)$ & $1.43(1.22)$ & $-0.24(0.44)$ \\
\hline Age & $0.00(0.01)$ & $-0.01(0.03)$ & $0.00(0.01)$ & $-0.01(0.01)$ & $-0.03(0.04)$ & $-0.01(0.01)$ \\
\hline Mental health & $-0.42(0.16)^{*}$ & $-0.83(0.44)$ & $-0.31(0.16)^{*}$ & $-0.13(0.24)$ & $-0.47(0.63)$ & $0.03(0.24)$ \\
\hline Physical health & $-0.64(0.17)^{\ddagger}$ & $-0.99(0.48)^{*}$ & $-0.54(0.16)^{\dagger}$ & $-0.75(0.25)^{\dagger}$ & $-1.28(0.68)$ & $-0.58(0.25)^{*}$ \\
\hline Adjusted $R^{2}$ & & & & $4.8 \%$ & $6.7 \%$ & $2.8 \%$ \\
\hline
\end{tabular}

a Model 1 was unadjusted.

${ }^{b}$ Model 2 was adjusted for race/ethnicity, marital status, seeing other people $>5 x$ per week, religious services, living at the same address, age, self-rated mental health, self-rated physical health, and sex.

${ }^{*} P<0.05 ;{ }^{\dagger} P<0.01 ; \neq P<0.001$.

est., estimate; SE, standard error. 


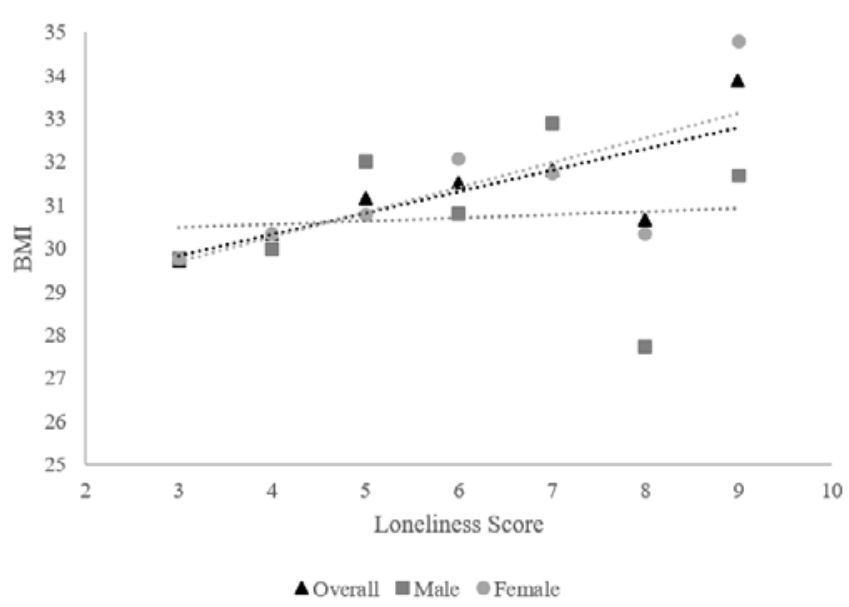

Figure 1. Relationship between loneliness score and adjusted mean body mass index (BMI), overall and stratified by sex.

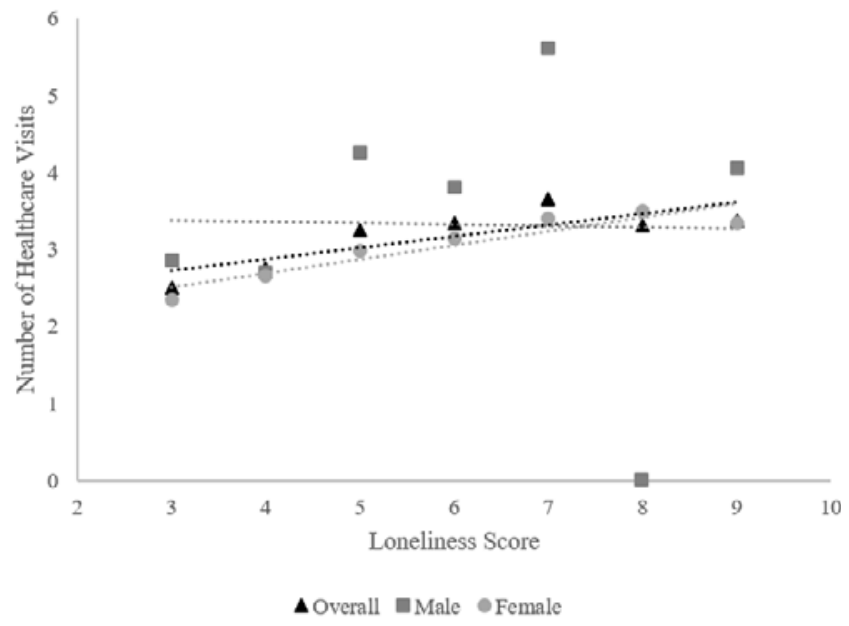

Figure 2. Relationship between loneliness score and adjusted mean number of health care visits, overall and stratified by sex.

In males and females, loneliness was not associated with health care utilization per either model (Table 3; Figure 2). However, among females, health care utilization was positively associated with higher participation in religious services $(\mathrm{P}=0.04)$ and negatively associated with self-reported mental $(\mathrm{P}=0.05)$ and physical health $(\mathrm{P}=0.02)$ per Model 2 (Table 3$)$.

\section{DISCUSSION}

This study aimed to determine the relationships between loneliness, BMI, and health care utilization in adult family medicine patients in Pennsylvania. We originally hypothesized that greater BMI would be associated with a higher loneliness score, and our initial findings supported this supposition; however, this relationship was not significant after adjustment for covariates. When stratifying by sex, BMI in males was not associated with loneliness but it was positively associated for females, meaning that females with greater BMI had higher loneliness scores.

Our results differ from those in the literature regarding the association between loneliness and obesity. Prior literature suggested that loneliness increases with obesity onset in men but not women. ${ }^{36}$ This could be related to our patient sample of the primary care population in Pennsylvania, a group that had not been studied previously. Many in our sample live in more rural and suburban areas. According to a Centers for Disease Control and Prevention report, adults living in nonmetropolitan (rural) counties are more likely to be obese than adults in metro (urban) counties. ${ }^{37}$ Additionally, those living in suburban areas are often limited in travel choices, forcing more reliance on travel by car to local destinations and decreasing opportunity for physical activity. ${ }^{38}$

We also hypothesized that higher loneliness would be associated with greater health care utilization; however, we did not find an association between these variables in the unadjusted or adjusted multivariable models. The study being conducted in primary care offices may have created a biased sample, as the participants were utilizing health care services when recruited for the study. Those that would be less likely to utilize health care resources may not have come to the office in the first place. Nevertheless, we did find that decreased health care utilization was associated with Hispanic ethnicity, marital status, and self-reported mental and physical health. When stratifying by sex, males were less likely to utilize health care resources if they were married, living with a partner, or had higher selfreported physical health. Females were more likely to utilize health care resources if they attended religious services regularly and less likely to utilize health care resources if they had higher self-reported mental and physical health.

There were additional notable findings that may be potentially relevant to patient care. BMI was negatively associated with attending religious services 1-2 times per month (or more), as well as self-reported physical health. Furthermore, a higher BMI in women was associated with 
greater loneliness and lower participation in religious services. Individuals with higher BMI may be prone to social exclusion because of societal norms around body image. ${ }^{24}$ Those who are overweight or obese may be less likely to attend religious services due to experiences of discrimination and feeling like outsiders. ${ }^{25}$ While attending religious services is certainly not the only place one can build a sense of community and build support, it would be important to address BMI as a potential barrier to attendance. We did find that higher participation in religious services was associated with increased health care utilization. Frequent attendance at religious services is associated with significantly lower risk of all-cause, cardiovascular, and cancer mortality among women. ${ }^{39}$ It may be beneficial for primary care providers to discuss community engagement with patients and to do outreach to local communities.

Of note, most people included in the study (about 75\% of participants) had 3 or fewer health care visits in a year. The upper quartile of visits was between 3 and 48 visits in a year. We do not know based on the data what a "normal" amount of visits would be for this population. We do not have a sense of whether increased utilization in those with a higher BMI is indicative of inappropriate use of resources or as a sign that patients with increased utilization (more than 3 visits in a year) are perhaps sicker and require extra care.

We also found that increasing BMI was positively associated with self-reported mental health in females. This is consistent with a 2020 report that found individuals categorized as overweight or obese with higher body satisfaction and elevated positivity were more likely to report being happy than other participants in the study. ${ }^{40}$ Moreover, health care providers could enhance their promotion of body positivity and discussion of engagement in life-fulfillment goals as part of weight-related discussions with patients. ${ }^{40}$ It seems intuitive that those who reported good self-reported mental and physical health utilized health care less frequently. Yet, it is still encouraged (and usually covered by insurance) that everyone has an annual wellness visit to engage in preventive care. Meeting with a PCP regularly can aid in reviewing healthy lifestyle habits in an effort to prevent common medical issues (eg, diabetes, cardiovascular disease).

\section{Limitations}

Our study has several limitations. Due to the convenience sample methodology, our population may not be representative of the general population. Specifically, some offices had higher sampling rates than others related to the activity of the physician champion who was engaged at that office. Furthermore, we assessed height and weight through self-report rather than by measurement in clinic. While self-reported data may introduce bias, adjusting for sociodemographic factors may have reduced this bias. ${ }^{41}$

This study captured a 1-week period in July, which may have impacted responses due to increased chance for recent travel and engagement in more outdoor activities during the summer, affecting self-reported health. Finally, given the cross-sectional nature of this survey, we are unable to determine the directional relationships among loneliness, BMI, and health care utilization.

\section{CONCLUSIONS}

There was a positive association between loneliness and body mass index in female primary care patients, based on multivariable analysis. However, no statistically significant association was found between loneliness and health care utilization. Given the relationship between loneliness and poor health outcomes such as obesity, hypertension, and stroke as well as increased mortality, it would be prudent to consider loneliness assessments of patients in the primary care setting to identify patients who may be at risk and engage them in preventive care. Primary care physicians can work with patients to identify local resources for community engagement, as there is no one-size-fits-all, and interventions should be tailored to suit the needs of individuals, specific groups, or the degree of loneliness experienced. ${ }^{42}$ Helpful resources may include local community centers, online support groups, and initiatives such as the Campaign to End Loneliness (campaigntoendloneliness.org).

\section{Patient-Friendly Recap}

- Authors investigated whether the combination of loneliness and obesity, two characteristics independently associated with poor physical and mental health, related to how frequently patients utilized health care services.

- Adult patients presenting to any of 7 primary care clinics were surveyed regarding age, sex, race, socialization, body mass index, degree of loneliness, and frequency of health care visits.

- Elevated body mass index was associated with loneliness in female patients; however, no evidence of increased health care use in obese or lonely patients was observed.

- Physicians could consider assessing loneliness in some patients and, when identified, provide local resources, encouragement, or advice on ways to further engage with the community. 


\section{Author Contributions}

Study design: Oser, Roy, Parascando, Mullen, Moss. Data acquisition or analysis: Oser, Parascando, Moss. Manuscript drafting: Oser, Parascando, Radico, Moss. Critical revision: Roy, Mullen, Reedy-Cooper.

\section{Conflicts of Interest}

None.

\section{Funding Sources}

This study was funded by the Thomas L. and Jean L. Leaman Research Endowment, Department of Family and Community Medicine, Penn State College of Medicine.

\section{References}

1. National Academies of Sciences, Engineering, and Medicine. Social Isolation and Loneliness in Older Adults: Opportunities for the Health Care System. The National Academies Press; 2020. CrossRef

2. Holt-Lunstad J, Smith TB, Baker M, Harris T, Stephenson D. Loneliness and social isolation as risk factors for mortality: a meta-analytic review. Perspect Psychol Sci. 2015;10:227-37. CrossRef

3. Heinrich LM, Gullone E. The clinical significance of loneliness: a literature review. Clin Psychol Rev. 2006;26: 695-718. CrossRef

4. Hawkley LC, Masi CM, Berry JD, Cacioppo JT. Loneliness is a unique predictor of age-related differences in systolic blood pressure. Psychol Aging. 2006;21:152-64. CrossRef

5. Holt-Lunstad J, Smith TB. Loneliness and social isolation as risk factors for CVD: implications for evidence-based patient care and scientific inquiry. Heart. 2016;102:987-9. CrossRef

6. Petitte T, Mallow J, Barnes E, Petrone A, Barr T, Theeke L. A systematic review of loneliness and common chronic physical conditions in adults. Open Psychol J. 2015;8(Suppl 2):113-32. CrossRef

7. Beutel ME, Klein EM, Brähler E, et al. Loneliness in the general population: prevalence, determinants and relations to mental health. BMC Psychiatry. 2017;17(1):97. CrossRef

8. Boden-Albala B, Litwak E, Elkind MSV, Rundek T, Sacco RL. Social isolation and outcomes post stroke. Neurology. 2005;64:1888-92. CrossRef

9. Ebrahim S, Barer D, Nouri F. Affective illness after stroke. Br J Psychiatry. 1987;151:52-6. CrossRef

10. Löfvenmark C, Mattiasson AC, Billing E, Edner M. Perceived loneliness and social support in patients with chronic heart failure. Eur J Cardiovasc Nurs. 2009;8:251-8. CrossRef

11. Murthy V. Work and the loneliness epidemic: reducing isolation at work is good for business. Harvard Business Review. Published September 26, 2017; accessed May 20, 2018. https:// hbr.org/cover-story/2017/09/work-and-the-loneliness-epidemic

12. Holt-Lunstad J, Robles TF, Sbarra DA. Advancing social connection as a public health priority in the United States. Am Psychol. 2017;72:517-30. CrossRef

13. Luchetti M, Lee JH, Aschwanden D, et al. The trajectory of loneliness in response to COVID-19. Am Psychol. 2020;75:897-908. CrossRef

14. Saltzman LY, Hansel TC, Bordnick PS. Loneliness, isolation, and social support factors in post-COVID-19 mental health. Psychol Trauma. 2020;12(S1)S55-7. CrossRef
15. Mullen RA, Tong S, Sabo RT, et al. Loneliness in primary care patients: a prevalence study. Ann Fam Med. 2019;17:108-15. CrossRef

16. Stecker T, Sparks S. Prevalence of obese patients in a primary care setting. Obesity. 2006;14:373-6. CrossRef

17. Musich S, MacLeod S, Bhattarai GR, et al. The impact of obesity on health care utilization and expenditures in a Medicare supplement population. Gerontol Geriatr Med. 2016;2:2333721415622004. CrossRef

18. Okosun IS, Choi S, Matamoros T, Dever GE. Obesity is associated with reduced self-rated general health status: evidence from a representative sample of white, black, and Hispanic Americans. Prev Med. 2001;32:429-36. CrossRef

19. Gerst-Emerson K, Jayawardhana J. Loneliness as a public health issue: the impact of loneliness on health care utilization among older adults. Am J Public Health. 2015;105:1013-9. CrossRef

20. Jacobs JM, Cohen A, Hammerman-Rozenberg R, Stessman J. Global sleep satisfaction of older people: the Jerusalem Cohort Study. J Am Geriatr Soc. 2006;54:325-9. CrossRef

21. Morse SA, Ciechanowski PS, Katon WJ, Hirsch IB. Isn't this just bedtime snacking? The potential adverse effects of night-eating symptoms on treatment adherence and outcomes in patients with diabetes. Diabetes Care. 2006;29:1800-4. CrossRef

22. Luppino FS, de Wit LM, Bouvy PF, et al. Overweight, obesity, and depression: a systematic review and meta-analysis of longitudinal studies. Arch Gen Psychiatry. 2010;67:220-9. CrossRef

23. Jantaratnotai N, Mosikanon K, Lee Y, McIntyre RS. The interface of depression and obesity. Obes Res Clin Pract. 2017;11:1-10. CrossRef

24. Jung FU, Luck-Sikorski C. Overweight and lonely? A representative study on loneliness in obese people and its determinants. Obes Facts. 2019;12:440-7. CrossRef

25. Schumaker JF, Krejci RC, Small L, Sargent RG. Experience of loneliness by obese individuals. Psychol Rep. 1985;57:1147-54. CrossRef

26. Henriksen RE, Nilsen RM, Strandberg RB. Loneliness as a risk factor for metabolic syndrome: results from the HUNT study. J Epidemiol Community Health. 2019;73:941-6. CrossRef

27. Whisman MA. Loneliness and the metabolic syndrome in a population-based sample of middle-aged and older adults. Health Psychol. 2010;29:550-4. CrossRef

28. Wong JJ, Hood KK, Breland JY. Correlates of health care use among White and minority men and women with diabetes: an NHANES study. Diabetes Res Clin Pract. 2019;150:122-8. CrossRef

29. Ogden CL, Fakhouri TH, Carroll MD, et al. Prevalence of obesity among adults, by household income and education United States, 2011-2014. MMWR Morb Mortal Wkly Rep. 2017;66:1369-73. CrossRef

30. Hughes ME, Waite LJ, Hawkley LC, Cacioppo JT. A short scale for measuring loneliness in large surveys: results from two population-based studies. Res Aging. 2004;26:655-72. CrossRef

31. Russell D, Peplau LA, Cutrona CE. The revised UCLA Loneliness Scale: concurrent and discriminant validity evidence. J Pers Soc Psychol. 1980;39:472-80. CrossRef

32. Steptoe A, Shankar A, Demakakos P, Wardle J. Social isolation, loneliness, and all-cause mortality in older men and women. Proc Natl Acad Sci U S A. 2013;110:5797-801. CrossRef 
33. Ferraro KF, Wilkinson LR. Alternative measures of selfrated health for predicting mortality among older people: Is past or future orientation more important? Gerontologist. 2015;55:836-44. CrossRef

34. Behavioral Risk Factor Surveillance System (BRFSS). 2018 BRFSS Questionnaire Published January 18, 2018. https:// www.cdc.gov/brfss/questionnaires/pdf-ques/2018 BRFSS English_Questionnaire.pdf

35. Base SAS 9.4 Procedures Guide, Seventh Edition. SAS Institute Inc.; 2017.

36. Hajek A, König HH. Obesity and loneliness. Findings from a longitudinal population-based study in the second half of life in Germany. Psychogeriatrics. 2019;19:135-40. CrossRef

37. Lundeen EA, Park S, Pan L, O'Toole T, Matthews K, Blanck HM. Obesity prevalence among adults living in metropolitan and nonmetropolitan counties - United States, 2016. MMWR Morb Mortal Wkly Rep. 2018;67:653-8. CrossRef

38. Vandegrift D, Yoked T. Obesity rates, income, and suburban sprawl: an analysis of US states. Health Place. 2004;10:221-9. $\underline{\text { CrossRef }}$
39. Li S, Stampfer MJ, Williams DR, VanderWeele TJ. Association of religious service attendance with mortality among women. JAMA Intern Med. 2016;176:777-85. CrossRef

40. Godoy-Izquierdo D, González-Hernández J, RodríguezTadeo A, et al. Body satisfaction, weight stigma, positivity, and happiness among Spanish adults with overweight and obesity. Int J Environ Res Public Health. 2020;17(12):4186. CrossRef

41. Stommel M, Schoenborn CA. Accuracy and usefulness of BMI measures based on self-reported weight and height: findings from the NHANES \& NHIS 2001-2006. BMC Public Health. 2009;9:421. CrossRef

42. Fakoya OA, McCorry NK, Donnelly M. Loneliness and social isolation interventions for older adults: a scoping review of reviews. BMC Public Health. 2020;20(1):129. CrossRef

(C) 2021 Advocate Aurora Health, Inc. 